\title{
A IMPORTÂNCIA DO LÚDICO NA APRENDIZAGEM DA CRIANÇA
}

\author{
Edna Rodrigues Marques ${ }^{1}$
}

RESUMO: O presente trabalho acadêmico tem como temática a importância da ludicidade no ambiente educativo, visto que o lúdico é uma ferramenta pedagógica que influencia qualitativamente a atuação docente em sala de aula. Sabe-se que as brincadeiras já fazem parte da vida da criança desde seu nascimento, sendo um poderoso instrumento capaz de instigar e principalmente promover a aprendizagem, levando a criança a valorizar e expressar seus conhecimentos, interagir com novos conhecimentos e adentrar ao conhecimento acadêmico. Considerando as pesquisas bibliográficas realizadas nesta produção escrita, constatou-se a necessidade de implementar as atividades lúdicas dentro da sala de aula, considerando que as mesmas potencializam e auxiliam no desenvolvimento das crianças, nos diferentes aspectos: cognitivo, físico, psicológico, motor e social. Comprovou-se que o lúdico é um fator positivo na construção do conhecimento das crianças, durante a infância, desenvolvendo nelas a imaginação, raciocínio, criatividade e espontaneidade na construção do sistema de representação (leitura e escrita). Para tanto, é fundamental a reflexão sobre a prática docente no dia-a-dia das instituições de ensino, a fim de modificá-la, no que se refere à utilização deste importante recurso pedagógico.

Palavras-Chaves: Lúdico. Aprendizagem. Criança. Brincar. Educar.

ABSTRACT: This paper proposes a vision of vital importance on the issue of playfulness inserted in the educational process, it is essential that teacher education is steeped in turning their syllabus in activities that will elucidate and challenge children to learn for pleasure. Aims to understand the meaning of the play and its importance in the

\footnotetext{
I Pós-graduada em Cultura Gerencial pela FGV do RJ (2010) e Gestão Escolar (2008), graduada em Licenciatura Plena em Pedagogia pela UEG (2002). Possui 29 anos de carreira efetiva na rede estadual de ensino atuando em diversas áreas: docência da I $^{\underline{a}}$ Fase do ensino fundamental, docência da Educação de Jovens e Adultos, Gestora de Unidade escolar, gestão da Subsecretaria Regional de Educação, Gerente de Gestão Escolar da SEDUC, sendo responsável pelo acompanhamento e formação das equipes gestoras e das unidades escolares estaduais de Goiás. Atuou como Tutora de Gestão no Projeto Multicurso com a formação de professores e gestores do ensino médio da rede pública de goiás. Professora universitária na FAESP e ainda Professora Formadora dos cursos: Deficiência Mental no Contexto da Educação Inclusiva $\mathbf{I}^{\underline{\mathbf{a}}}$ e $2^{\underline{a}}$ Edição, Atendimento Educacional Especializado do Programa de Formação Continuada de Professores na Educação Especial I ${ }^{\underline{a}}$, $2^{-a}$ e $3^{\underline{a}}$ Edição - MEC/SEESP/UEG/SEDUC - GO e pelo Instituto QUALIS - GO. Exerceu função de docente universitária, Orientadora de Trabalhos de Conclusão de Curso e de Avaliadora em Bancas de Trabalho de Conclusão de Curso na Universidade Estadual de Goiás. Atuou como Formadora Regional do Pacto Nacional pela Alfabetização na Idade Certa - PNAIC, pela UNIVERSIDADE ESTADUAL DE GOIÁS no período de 2017 e 2018. Atualmente é professora de Atendimento Educacional Especializado. E-mail:ednarodriguesmarques@hotmail.com
} 
development of language in children. Thus, designing games as a pleasurable and enriching act of traditions and knowledge, it becomes something conducive to profound reflections of current pedagogical practices. We know that the games are already part of a child's life from birth, being a powerful tool capable of instigating and mainly promote learning, taking the child to value and express their cultures and interacting with new cultures and experiences entering the world of knowledge, full of prospects and possibilities of developing their skills and capabilities where the real world and the imaginary are confronted constantly building roads through playful activities that will guide and help the child develop their motor, cognitive, and social potential their knowledge.

Keywords: Recreation. Learning. Child. Play. Educate.

\section{INTRODUÇÃO}

A presente pesquisa tem por objetivo propor e elucidar conceitos de atividades lúdicas e sua importância para o desenvolvimento da aprendizagem da criança na Educação Infantil, valorizando o espaço da sala de aula como instrumento facilitador e instigador dessa aprendizagem. Assim, faz-se necessário entender e identificar o lúdico em suas entrelinhas como recurso pedagógico essencial para a construção do conhecimento da criança. A utilização de jogos, danças, músicas, brincadeiras no processo pedagógico desperta na criança o gosto pela vida e leva-as a enfrentar os desafios que surgem. Este trabalho irá demonstrar o quanto o lúdico pode ser um instrumento indispensável no processo de ensino/aprendizagem. Assim, a ludicidade através de jogos, brinquedos e brincadeiras são de fundamental importância para desenvolvimento cognitivo, motor e afetivo das crianças.

O lúdico será enfocado como uma ferramenta propulsora de situações no âmbito educacional que proporciona não só um meio real de ensino/aprendizagem, mas também como uma maneira de instigar os educadores a procurar e adquirir outros métodos didáticos e manejos diários de forma prazerosa e ao mesmo tempo recheada de aprendizagens significativas. Através das atividades lúdicas é possível criar situações para que os alunos adquiram conhecimentos, aprendam trabalhar em equipe, desenvolve a imaginação, criatividade e capacidade de adaptação em diferentes ambientes.

Este trabalho enfocará em primeiro momento a origem do lúdico e sua evolução na aprendizagem das crianças, dando um grande enfoque a importância do brincar como sendo um ato fundamental para o desenvolvimento e formação do conhecimento da 
criança. Essa temática tem como objetivo analisar as concepções dos professores sobre a importância do lúdico no desenvolvimento integral da criança, onde poderão adquirir novos métodos para serem desenvolvidos com o uso do lúdico, partindo do princípio de que as crianças aprendem brincando, tendo, portanto, a convicção de que essa temática poderá contribuir para uma possível reflexão sobre a ação pedagógica e como ferramenta de socialização da criança.

Será exposto o papel pedagógico do brincar no qual possui a função de construir alicerces, onde as crianças através de brincadeiras, uma vez que bem conduzidas, serão impulsionadas a experimentarem um mundo repleto de curiosidades e autoconfiança. A formação e o papel do professor serão discutidos com grande ênfase, uma vez que a formação do professor necessita ser contínua, este profissional precisa ter como objetivo principal a verdadeira formação que o leve a alcançar seus objetivos, que é o aprender com qualidade e eficácia.

A metodologia utilizada na realização deste trabalho foi a pesquisa bibliográfica de autores renomados, como: Almeida (1995), Santos (2001), Vygotsky (1984), Piaget (1986), RCNEI (1998), dentre outros. Em todo o trabalho será evidenciado e validado à importância de trabalhar atividades lúdicas em sala de aula, quebrando paradigmas e tabus criados por profissionais que culmina nas dificuldades de alguns educadores em trabalhar com ações divertidas e interessantes em seus planejamentos.

Por fim, apresentaremos a inegável importância das atividades lúdicas desenvolvidas em sala de aula pelos professores, a fim de que se tornem em ambientes atrativos e prazerosos, tanto para educandos como para educadores.

\section{LÚDICO: ORIGEM E EVOLUÇÃO NO CAMPO EDUCACIONAL}

O lúdico sempre esteve presente na vida cotidiana do ser humano. A atividade lúdica é algo que intervém tanto o universo infantil como o adulto há muito tempo. $\mathrm{O}$ homem sempre brincou de diversas maneiras e formas. A palavra lúdico é de origem latina, ludus que significa jogo e é definida como uma peça fundamental para auxiliar e dar suporte ao professor em sala de aula. Assim, o uso da ludicidade como ferramenta metodológica contribui para a construção de sua aprendizagem, e também para o desenvolvimento da memória e imaginação da criança. 
O lúdico tem sua origem na palavra latina "ludus" que quer dizer "jogo". Se achasse confinado a sua origem, o termo lúdico estaria se referindo apenas ao jogar, ao brincar, ao movimento espontâneo. A evolução semântica da palavra "lúdico", entretanto, não parou apenas nas suas origens e acompanhou as pesquisas de Psicomotricidade. O lúdico passou a ser reconhecido como traço essencial de psicofisiologia do comportamento humano. De modo que a definição deixou de ser o simples sinônimo de jogo. As implicações da necessidade lúdica extrapolaram as demarcações do brincar espontâneo. (ALMEIDA, 2009, p. or).

Ao levar em consideração o sentido original da palavra lúdico, este termo estaria se referindo apenas ao jogo, ao brincar, ao movimento espontâneo. Entretanto, a palavra lúdico com o passar dos tempos, ganhou outros significados de modo que sua definição deixou de ser um simples sinônimo de jogo, de brincar e passou ser compreendida como uma ferramenta facilitadora da compreensão e formação do conhecimento da criança.

O lúdico há muito tempo vem atraindo a atenção do sistema educacional, sendo tema de debates e discussões levando os educadores a imbuírem em seus objetivos e planejamentos. Nessa perspectiva, o aprendizado vem tomando nos últimos anos, novas concepções e novos rumos, na tentativa de atender uma sociedade que a cada dia está mais impregnada de informações e inovações. Assim o lúdico não deve ser visto apenas como uma simples forma de brincadeira e diversão, mas sim como uma ferramenta que proporciona a aquisição de conhecimentos. Segundo Piaget (1986, p.16) "O desenvolvimento da criança acontece através do lúdico. Ela precisa brincar para crescer, precisa do jogo como forma de equilibração com o mundo". Em função disso observa-se que o lúdico é de fundamental importância na vida criança, pois través dos jogos, brincadeiras elas se interagem, socializam-se, reproduz suas vivências, assim, constrói sua realidade, seu aprendizado. Dessa maneira, no campo da educação as atividades lúdicas assumiram características próprias e hoje pode-se afirmar que é um agente de mudança do ponto de vista educacional, capaz de proporcionar o desenvolvimento da criança

É preciso lembrar que o lúdico deve sempre ser trabalhado de maneira adequada no ambiente escolar para que possa adquirir conhecimentos, melhorando assim seu desenvolvimento pessoal, social e cultural. Isto é fundamental para uma melhor saúde mental, socialização, comunicação e construção do conhecimento, assim a criança sentirá mais feliz e segura na escola.

A brincadeira além de contribuir e influenciar na formação da criança, possibilitando um crescimento sadio, um enriquecimento permanente, integra-se ao mais alto espírito de uma prática democrática enquanto investe em uma 
produção séria do conhecimento. Sua prática exige a participação franca, criativa, livre, crítica, promovendo a interação social e tendo em vista o forte compromisso de transformação e modificação do meio. (ALMEIDA, 1998, p.57).

$\mathrm{Na}$ Educação Infantil, o brincar estimula a inteligência da criança, faz com que ela liberte sua imaginação, desenvolva sua criatividade, concentração e sua atenção, isto é fundamental para que a criança possa entender melhor as atividades propostas em sala de aula. Daí a importância da criança vivenciar o lúdico em sua prática total, para melhor socializar-se e se relacionar com as pessoas.

O professor que trabalha com o lúdico propicia à criança viver de forma integral e criativa o que lhe é proposto, como recortar, pintar, desenhar, correr. "A educação pela via da ludicidade propõe-se a uma nova postura existencial, cujo paradigma é um novo sistema de aprender brincando, inspirado numa concepção de educação para além da instrução”. (SANTOS, 200I, p. 53). Com base nisto, fica claro que por meio de atividades lúdicas, a criança expressa, assimila e constrói a sua realidade. A criança poderá aprender com qualidade e significados, com isso seu desenvolvimento será completo e seu aprendizado acontecerá naturalmente.

\section{A IMPORTÂNCIA DO BRINCAR NO DESENVOLVIMENTO INFANTIL}

As crianças ao praticarem as atividades que gostam, irão brincar com prazer, jogarão com alegria, suas mentes estarão abertas ao conhecimento. No entanto, só irão concretizar o ensino-aprendizagem quando o jogo, o brincar estiver inserido num contexto voltado a atender as necessidades existentes no ambiente escolar, proporcionando um melhor desenvolvimento das capacidades da criança.

Educar significa, portanto, propiciar situações de cuidados, brincadeiras e aprendizagens orientadas de forma integrada e que possam contribuir para o desenvolvimento das capacidades infantis de relação interpessoal, de ser e estar com os outros em uma atitude básica de aceitação, respeito e confiança, e o acesso, pelas crianças, aos conhecimentos mais amplos da realidade social e cultural. Neste processo, a educação poderá auxiliar o desenvolvimento das capacidades de apropriação e conhecimento das potencialidades corporais, afetivas, emocionais, estéticas e éticas, na perspectiva de contribuir para a formação de crianças felizes e saudáveis. (BRASIL, 1998, p. 23).

Dessa forma, os jogos educativos são fundamentais para estimular, instigar o crescimento do ensino-aprendizagem dos alunos. Sua importância é percebida ao longo dos tempos, principalmente ao levar em consideração seu poder de transformação e construção 
da personalidade e conhecimento da criança. $O$ jogo tem por objetivo trazer alegria e prazer para a sala de aula ao mesmo tempo em que proporciona o divertimento para a criança, adolescente e adulto, promovendo assim o aprendizado, seja formal ou informal, podendo acontecer dentro e fora da escola. Segundo Claparéde (1958. p. 36), "a criança é um ser feito para brincar, e que o jogo é um artifício que a natureza encontrou para envolver a criança numa atividade útil ao seu desenvolvimento físico e mental”. Assim, as brincadeiras e os jogos quando trabalhados através de metodologias lúdicas, proporcionam as crianças pleno sucesso no que diz respeito à formação de seus conhecimentos. Deve-se lembrar que as atividades lúdicas também têm um papel importante no desenvolvimento da criança, uma vez que propicia a integração e socialização da criança com seus colegas no ambiente escolar.

\begin{abstract}
Não somente para cultivar a autonomia da criança, mas para que seja preservada sua motivação intrínseca. Entretanto, os conhecimentos e a intuição do educador saberão fazer uma pré-escolha, construir um contexto lúdico adequado e disponibilizar para ela uma variedade de oportunidades que possibilite um nível de operação satisfatório, dentro do qual ela possa, de forma criativa e prazerosa, evoluir e aprender. (CUNHA, 2004, p.12).
\end{abstract}

O brincar é uma atividade muito importante para a criança, pois enquanto brinca, ela entra em contato com o meio e com outras crianças, esse contato proporciona o desenvolvimento de seu comportamento em está formação. Esta atividade surge e predomina naturalmente no período da infância e está diretamente relacionada ao desenvolvimento da aprendizagem na criança. Através de experiências vividas e adquiridas por meio das brincadeiras, estabelecem-se vínculos entre alunos, professores e escola, os quais favorecem a construção de seus conhecimentos. Segundo Vygotsky (1984) é brincando e jogando que a criança revela seu estado cognitivo, visual, auditivo, tátil, motor e seu modo de aprender, como também sua maneira de se relacionar com as pessoas, coisas e símbolos. Assim, cabe ao professor criar situações de ensino/aprendizagem, onde a criança possa ter liberdade para escolher como e com quem brincar.

[...] o professor é mediador entre as crianças e os objetos de conhecimento, organizando e propiciando espaços e situações de aprendizagens que articulem os recursos e capacidades afetivas, emocionais, sociais e cognitivas de cada criança aos seus conhecimentos prévios e aos conteúdos referentes aos diferentes campos de conhecimento humano. $\mathrm{Na}$ instituição de educação infantil o professor constitui-se, portanto, no parceiro mais experiente, por excelência, cuja função é propiciar e garantir um ambiente rico, prazeroso, saudável e não discriminatório de experiências educativas e sociais variadas. (BRASIL, 1998, p. 30) 
Em função disso é possível observar que o professor atua como mediador entre a criança e o objeto de conhecimentos, onde é dever dele organizar e proporcionar à criança situações que propicie a ela adquirir conhecimentos. Isto é possível através de um ambiente escolar alegre, prazeroso, inclusivo, onde o professor sempre trabalha com

diferentes métodos de ensino em suas aulas, dentre os quais as brincadeiras educativas são uma prática constante.

Certo é que a ludicidade deve permear o ambiente escolar, pois seu uso em sala de aula contribui para a formação do conhecimento da criança. É necessário que o professor tenha consciência que na brincadeira as crianças recriam e estabilizam aquilo que sabem sobre as diversas esferas do conhecimento, em uma atividade espontânea e imaginativa. O brinquedo é um excelente objeto que auxilia a criança a adquirir conhecimento.

O lúdico deve permear a prática escolar, fluindo e manifestando-se na criatividade. Portanto, é necessário que os adultos, pais e educadores tenham convicção e levem a sério a importância do brincar, pois a criança em idade préescolar começa a experimentar necessidades, em que os desejos não realizáveis podem ser realizados por meio do brinquedo, como um mundo imaginário, no qual a criança cria e imagina, e ao imaginar ela brinca, pois o brinquedo proporciona a mediação entre o real e o imaginário (VYGOSTKY, 1998, apud SILVA, 2006, p. 67).

Sem sombra de dúvidas o brincar é parceiro da aprendizagem é a essência da infância e seu uso em sala de aula, está diretamente relacionado com a produção do conhecimento e desenvolvimento da criança. De acordo com Desgualdo (2008), a brincadeira contribui para o processo de socialização das crianças, estimula o desenvolvimento de suas habilidades e aquisição de novos conhecimentos.

Segundo o Referencial Curricular Nacional da Educação Infantil (1998), o professor não precisa ensinar a criança a brincar, pois este é um ato que surgi naturalmente, mas sim planejar e organizar situações para que as brincadeiras aconteçam de maneira diversificada, proporcionando às crianças a possibilidade de escolher os temas, papéis, objetos e companheiros para brincar. Dessa forma, poderão construir de maneira pessoal e independente suas emoções, sentimentos, conhecimentos e regras sociais.

Com base no que foi exposto ressalta-se que na instituição de educação infantil o professor constitui-se num parceiro da criança, com função de planejar, organizar e propiciar um ambiente rico, prazeroso, saudável para que as brincadeiras aconteçam como 
meio de interação social e construção de conhecimentos e nunca discriminatório as diversas experiências educativas.

\section{A IMPORTÂNCIA DO LÚDICO COMO RECURSO PEDAGÓGICO}

Ao trabalhar a ludicidade no ambiente escolar por meio de jogos e brincadeiras percebe-se sua eficiência para o desenvolvimento físico e psicológico da criança, além de servir como um recurso que motiva o processo de ensino/aprendizagem. Para tanto é necessário que o professor reformule seus métodos, atitudes, conhecimentos e que estejam totalmente envolvidos neste processo. Para alcançar os objetivos esperados é necessário romper as barreiras existentes num modelo pré-instituído no ambiente escolar. A intervenção do professor no processo de ensino/aprendizagem torna-se uma esperança para que se quebrem esses limites, daí a importância de trabalhar com o lúdico em sala de aula.

De acordo Vygotsky (1998), o professor deve fazer o uso de jogos, brincadeiras e outras atividades, para que de forma lúdica a criança seja desafiada a pensar e a resolver situações problemas. Assim, percebe-se que através da ludicidade a criança pode vivenciar a aprendizagem numa perspectiva social e criativa. Com base nisto, deve-se considerar que a proposta principal do lúdico é contribuir para uma educação significativa no ambiente escolar.

[...] a atividade lúdica, o jogo, o brinquedo, a brincadeira, precisam ser melhor compreendidos e encontrar maior espaço para ser entendido como educação. $\mathrm{Na}$ medida em que os professores compreenderem toda sua capacidade potencial de contribuir no desenvolvimento infantil, grandes mudanças irão acontecer na educação e nos sujeitos que estão inseridos nesse processo (GOÉS, 2008, apud FANTACHOLI, 2009, p. or).

O lúdico promove o conhecimento, no entanto para que isto aconteça é preciso que os professores trabalhem com esta ferramenta em suas aulas. A intervenção do professor no processo de ensino-aprendizagem através da ludicidade é essencial para mudar as características atuais do sistema educacional.

Os jogos tornam a aula bem mais atraente, devolve ao professor seu papel como agente construtor do crescimento do aluno, elimina o desinteresse e, portanto, a indisciplina, devolvendo a escola a sua função de responsável por firmar pessoas mais completas (SANTOS, 200o, p. 42). 
Percebe-se a necessidade de desenvolver uma prática pedagógica eficiente, que instigue os alunos a pensar, a despertar o gosto pelos estudos, aprender de maneira significativa e prazerosa. Neste contexto, o professor em particular, está envolvido diretamente, uma vez que é ele o mediador do conhecimento.

\section{CONCLUSÃO}

Levando em consideração os estudos e as pesquisas realizadas na produção deste artigo, conclui-se que as atividades lúdicas exercem grande influência na aprendizagem e desenvolvimento da criança, pois ela aprende enquanto brinca. Através dos jogos, das brincadeiras a criança estabelece uma relação natural, onde aprende a se conhecer e a conhecer o outro.

Nessa perspectiva percebe-se que o lúdico também desenvolve a autoconfiança e autonomia das crianças, fundamental para possa adquirir novos conhecimentos. Proporciona o desenvolvimento da memória, da linguagem, da atenção, da percepção, da criatividade e das habilidades intelectuais da criança. O lúdico quando trabalhado adequadamente pelo docente, facilita a aprendizagem e o desenvolvimento da criança.

Conclui-se que é buscando novas maneiras de ensinar por meio do lúdico que conseguiremos uma educação de qualidade e que realmente consiga ir ao encontro dos interesses e necessidades dos estudantes.

\section{REFERÊNCIAS}

ALMEIDA, Anne. Ludicidade como Instrumento Pedagógico. Disponível em: 〈http//www.cdof.com.br/recre22.htm〉. Acessado em: o9 de Setembro 2014 às I4h:Ioh.

ALMEIDA, Paulo Nunes de. Educação Lúdica: Técnicas e Jogos Pedagógicos. São Paulo: Loyola, i995.

Educação Lúdica: Técnicas e Jogos Pedagógicos. 9. ed. São Paulo: Loyola, 1998.

BRASIL, Ministério da Educação e do Desporto. Secretaria de Educação Fundamental. Referencial Curricular Nacional para a Educação Infantil. vol. oı. Brasília: MEC/SEF, 1998.

CUNHA, Nylse Helena Silva. Brinquedo, Linguagem e Alfabetização. Petrópolis: Vozes, 2004 . 
CLAPARÈDE, Édouard. A Educação Funcional. $5^{\text {a }}$ ed. São Paulo: Editora Nacional, 1958.

DESGUALDO, Marianna. A Importância do Brincar no Desenvolvimento da Criança. Disponível em: http://www.webartigos.com/artigos/a-importancia-do-brincar-nodesenvolvimento-da-crianca/4448/. Acesso em: 24 de Setembro 2014 às 17:52h.

FANTACHOLI, Fabiane das Neves. A Importância do Brincar na Educação Infantil. Disponível em: http://monografias.brasilescola.com/educacao/a-importancia-brincar-naeducacao-infantil.htm. Acesso em: 25 de Setembro de 2014 às $17 \mathrm{~h}$.

PIAGET, Jean. A Linguagem e o Pensamento da Criança. São Paulo: Martins Fontes Editora Ltda, 1986.

A psicologia da Criança. Rio de Janeiro: Bertrand Brasil, 1998.

SANTOS, Santa Marli Pires dos. Brinquedoteca: A criança, o Adulto e o Lúdico. Petrópolis: Vozes, 2000.

A Ludicidade como Ciência. Petrópolis: Vozes, 20or.

SILVA, Ana Paula Lucena Cardoso da. O Lúdico na Educação Infantil: Concepções e Práticas dos Professores na Rede Municipal de Campo Grande-MS. Disponível em: http://site.ucdb.br/public/md-dissertacoes/7873-o-ludico-na-educacao-infantilconcepcoes-e-praticas-dos-professores-na-rede-municipal-de-campo-grande-ms.pdf. Acesso em: 16 de Outubro 2014 às 15:45h.

VYGOTSKY, Lev Semenovitch. A formação Social da Mente. São Paulo: Martins Fontes Editora Ltda, 1984.

A Formação Social da Mente. 6 ${ }^{\underline{a}}$ ed. São Paulo: Martins Fontes Editora Ltda, 1998.

Psicologia Pedagógica. São Paulo: Martins Fontes Editora Ltda, 200 I. 